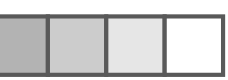

\title{
Três Propostas Político-Pedagógicas para se pensar o Ensino Jurídico Brasileiro em Tempos de Exceção: defendendo ideias revolucionárias
}

Three Political-Pedagogical Proposals to think Brazilian Legal Education in Times of Exception: defending revolutionary ideas.

Jarbas Ricardo Almeida Cunha ${ }^{1}$

\section{RESUMO}

Este artigo se propõe a discutir três ideias político-pedagógicas para o ensino jurídico brasileiro no contexto de exceção e de crise da representação jurídica atual. A primeira proposta é a pedagogia Marxista, sistematizada por pensadores soviéticos embalados pela Revolução Russa. A segunda é a pedagogia defendida e aplicada pelo Movimento dos Trabalhadores Rurais Sem Terra e a terceira proposta pedagógica será a defendida pelos doutrinadores do Direito Achado na Rua, tendo em Roberto Lyra Filho seu principal expoente. A metodologia utilizada neste trabalho será a revisão de

1 Doutorando em Direito, Estado e Constituição pela Universidade de Brasília (UnB). Graduação em Direito pela Universidade Federal de Ouro Preto (UFOP), Especialização em Direito Sanitário pela Fundação Oswaldo Cruz (Fiocruz) e Mestrado em Política Social pela Universidade de Brasília (UnB). 
literatura de tipo narrativo. Conclui-se que as propostas político-pedagógicas aqui apresentadas são importantes para a reflexão do ensino jurídico brasileiro, tendo como consequência a necessidade de um olhar crítico sobre o modus operandi dos sujeitos políticos que compõem o nosso Sistema de Justiça.

Palavras-chave: Pedagogia, Marxismo, Movimento dos Trabalhadores Rurais Sem Terra, Direito Achado na Rua, Ensino Jurídico.

\section{ABSTRACT}

This article proposes to discuss three political-pedagogical ideas for Brazilian legal education in the context of exception and crisis of the current legal representation. The first proposal is the Marxist pedagogy, systematized by Soviet thinkers encouraged by the Russian Revolution. The second is the pedagogy advocated and applied by the Movement of Landless Workers and the third pedagogical proposal will be defended by the lawyers The Law Found on the Street, with Roberto Lyra Filho as its main exponent. The methodology used in this work will be the literature review of narrative type. It is concluded that the political-pedagogical proposals presented here are important for the reflection of the Brazilian legal education, resulting in the need for a critical look at the modus operandi of the political actors that make up our Justice System.

Key-words: Pedagogy, Marxism, Movement of Landless Workers, The Law Found on the Street, Legal Education.

\section{INTRODUÇÃO}

Este artigo objetiva demonstrar como as pedagogias do campo crítico da educação podem auxiliar na formação de um pensamento ativo de transformação social no ensino jurídico brasileiro em tempos de exceção. 
Com esse objetivo, discorreremos sobre três propostas político-pedagógicas para se pensar a atuação dos sujeitos políticos dos órgãos do Sistema de Justiça: a) proposta político-pedagógica marxista-leninista, b) proposta do Movimento dos Trabalhadores Rurais Sem Terra (MST); c) proposta do Direito Achado na Rua, movimento criado pelo acadêmico Roberto Lyra Filho.

Para a consecução do objetivo delineado, utilizaremos a metodologia da revisão de literatura de tipo narrativa, em que consiste relatar "publicações amplas, apropriadas para descrever e discutir o desenvolvimento ou o 'estado da arte' de um determinado assunto, sob ponto de vista teórico ou contextual" (ROTHER, 2007, p.1).

Nesta revisão narrativa, utilizaremos coleta de material de pesquisa científica, sempre em uma tentativa de análise crítica pessoal do autor. Para esse intuito, foram utilizados basicamente livros sobre a temática, além de artigos científicos, ocasião em que analisamos de maneira dialética os principais conceitos e doutrinas e a interação realizada entre essas fontes.

\section{O CONSTRUCTO TEÓRICO DA CONJUNTURA DE EXCEÇÃO NO BRASIL}

Em uma conjuntura em que ocorre a fragilização do Estado Democrático e Social de Direito no Brasil, movimentos de direitos humanos e sociais representados por sem-tetos, feministas, LGBT's ${ }^{2}$, negros, indígenas, sem-terras, de ocupação de escolas, moradores de periferias, entre outros, se transformaram em constantes alvos de ataques por parte do Governo atual, via utilização de um aparato de segurança fortemente armado munido de violência extremamente desproporcional, caracterizando uma espécie de "novo urbanismo militar" (GRAHAM, 2016) ${ }^{3}$.

2 LGBT ou LGBTTT - Lésbicas, Gays, Bissexuais, Travestis, Transexuais e Transgêneros.

3 O autor classifica o novo urbanismo militar como "um conjunto de ideias, doutrinas e estratégias por meio das quais a polícia e as forças armadas dos governos e dos estados tentam condicionar a rápida expansão das cidades e das áreas urbanas ao controle social 
Ratifica-se, em nossa conjuntura, uma violência estrutural para fazer calar os defensores dos direitos humanos no Brasil, com perseguições, prisões e execuções de lideranças e militantes, ressoando o que há de pior em nossa história como país oligárquico, patriarcal e autoritário, como bem relata Chauí (2006, p. 138):

Por ser oligárquico e patrimonialista, o Estado percebe a sociedade civil como inimiga e perigosa, bloqueia as iniciativas dos movimentos sociais, sindicais e populares, instituindo mecanismos para impedir o trabalho dos conflitos e contradições sociais, econômicos e políticos.

Conflitos e contradições negam a imagem mítica da boa sociedade indivisa, pacífica e ordeira, por isso, recebem uma significação precisa: são sinônimo de perigo, crise, desordem e a eles se oferece uma única resposta: a repressão policial e militar para as camadas populares, e o desprezo condescendente para os opositores em geral (2006, p.138).

Essa característica de oligarquia conservadora em nosso país de modernidade tardia se reflete por searas mais amplas, como aspectos da democracia, do governo, mercado, comunicação e violência institucional. Pode-se complementar que no Brasil hodierno presencia-se um Estado de Direito Oligárquico, na descrição um tanto quanto rebelde e, ao mesmo tempo, irônica, de Rancière (2014):

Não vivemos em democracia. [...] Vivemos em Estados de direito oligárquicos, isto é, em Estados em que o poder da oligarquia é limitado pelo duplo reconhecimento da soberania popular e das liberdades individuais. Conhecemos bem as vantagens desse tipo de Estado, assim como seus limites. As eleições são livres. Em essência, asseguram a reprodução, com legendas intercambiáveis, do mesmo pessoal dominante, mas as urnas não são fraudadas e qualquer um pode se certificar disso sem arriscar a vida. A administração não é corrompida, exceto na

e político" (2016, p.16), mas também podemos constatar essa prática em meios rurais, principalmente na repressão de ocupações dos Sem-Terra e Atingidos por Barragens e de povos e comunidades indígenas e tribais. 
questão dos contratos públicos, em que ela se confunde com os interesses dos partidos dominantes. As liberdades dos indivíduos são respeitadas, à custa de notáveis exceções em tudo que diga respeito à proteção das fronteiras e à segurança do território. A imprensa é livre: quem quiser fundar um jornal ou uma emissora de televisão com capacidade para atingir o conjunto da população, sem a ajuda das potências financeiras, terá sérias dificuldades, mas não será preso. Os direitos de associação, reunião e manifestação permitem a organização de uma vida democrática, isto é, uma vida política independente da esfera estatal. Permitir é evidentemente uma palavra ambígua." (RANCIÈRE, 2014, p.94).

Sendo assim, esse contexto de radicalização da repressão e criminalização dos movimentos sociais por um país de tradição e cultura patriarcal, autoritária e patrimonialista, assim como a caracterização de um Estado de Direito Oligárquico, contribui também com a confirmação de duas teses centrais para a conjuntura que ora se apresenta: a doutrina do choque (KLEIN, 2008) e o estado de exceção (AGAMBEN, 2004).

Sobre a doutrina do choque, Klein (2008) analisa a ascensão e aplicação do neoliberalismo por meio de uma combinação que una choque e pavor, utilizando "janelas de oportunidade" como guerras, no caso do Iraque; crises econômicas, no caso das privatizações russas; e desastres ambientais, no caso da devastação do furacão Katrina nos Estados Unidos.

Especificamente em nosso contexto, há uma tempestade perfeita que propiciou uma doutrina de choque e pavor pelos governos de 2016 até hoje: crise política, crise econômica, crise ética e crise social. Tais fatores contribuíram para o rasgar da Constituição e dos direitos e garantias fundamentais, assim como a repressão desmedida contra movimentos sociais e libertários, aproveitando-se sobremaneira do estado de pavor e desorientação do então denominado campo democrático-popular, constituído pelas forças progressistas brasileiras.

Em consonância com essa narrativa, há também a formação de um Estado de Exceção (AGAMBEN, 2004), em que, segundo o autor, há 
a suspensão dos direitos estabelecidos e garantidos, contexto no qual o Estado de Exceção se torna estrutura juspolítica imposta ou mesmo estabelecida, com o beneplácito da própria sociedade, em face do conteúdo normativo vigente. Segundo Agamben (2004, p. 15) "O estado de exceção não é um direito especial (como o direito da guerra), mas, enquanto suspensão da própria ordem jurídica, define seu patamar ou seu conceito limite."

O jurista Pedro Estevam Serrano, em entrevista em sítio eletrônico ${ }^{4}$, contextualiza o conceito de Estado de Exceção em nossa região da América Latina, afirmando que o Sistema de Justiça é o principal responsável para a conflagração de uma espécie de Estado de Exceção Permanente:

Aqui na América Latina, a conclusão a que cheguei [...] é que o agente da exceção [...] é o sistema de justiça, ou direta ou indiretamente apoiando alguma medida do parlamento. Essas medidas de exceção têm sido produzidas em dois sentidos: interromper a democracia em alguns países e, em outros, manter um sistema de justiça voltado ao combate a um determinado inimigo, que é apresentado como bandido. A figura do bandido, em geral, é identificada com a pobreza.

Isso faz com que tenhamos um estado de exceção permanente, vivendo em conjunto com o estado democrático de direito, que governa os territórios ocupados pela pobreza através de, no caso brasileiro, uma força de ocupação territorial que é a PM. (Grifo nosso).

Com todos esses elementos que preenchem os vazios normativos, políticos e sociais no Brasil, que está caracterizado por muitas das formações teóricas e práticas de um Estado de Direito Oligárquico, de utilização de uma Doutrina do Choque e de um Estado de Exceção, se dá a radicalização de uma cadeia de violência para que sejam acionados vários dispositivos do modelo ultraneoliberal, representado

4 Disponível em: http://www.sul21.com.br/jornal/o-que-parece-estar-ocorrendo-na-americalatina-e-a-substituicao-da-farda-pela-togal Acesso em 19 de agosto de 2019. Para aprofundar no tema consultar SERRANO, Pedro. Autoritarismo e Golpes na América Latina: breve ensaio sobre jurisdição e exceção. São Paulo: Alameda, 2016. 
por retrocessos constitucionais, sanitários, educacionais, ambientais, econômicos e políticos, para a concretização de um estado mínimo de direitos e máximo na repressão e truculência com manifestantes que lutam por conquistas democráticas.

Em tempos difíceis, em que presenciamos ataques à democracia por meio de golpes parlamentares, sustentados pelo complexo jurídico-midiático-empresarial, num recrudescimento sem limites de uma nova onda conservadora que usa o combate seletivo à corrupção como pretexto para manter seus privilégios políticos, comportamentais e econômicos ${ }^{5}$, devemos procurar ousar no bom combate e propor analiticamente ideias com o intuito de honrar o cumprimento de nossa Constituição; por isso, defenderemos o ensino jurídico relacionado às três concepções pedagógicas como a Pedagogia Marxista, a Pedagogia do MST e o Direito Achado na Rua para tentarmos, num horizonte que seja próximo, a mudança dessa conjuntura político-jurídica.

\section{O MARXISMO E A PEDAGOGIA MARXISTA}

\subsection{O MARXISMO:}

Desde os eminentes teóricos do final do século XIX, passando pelas definições de linhagem ocidental, revolucionária e estruturalista do século $X X$, até a insurgência de novos desafios para reflexão crítica do século $X X I$, definir o marxismo sempre foi tarefa árdua, pois se trata de uma conceituação complexa por sua influência tanto na teoria acadêmica quanto nas ações de luta política. Inicialmente, utilizaremos como lastro epistêmico o Dicionário de Política (BOBBIO; MATEUCCI; PASQUINO, 1998) que define da seguinte forma a categoria conceitual denominada marxismo:

5 Está sendo amplamente divulgado pelo site The Intercept Brasil o conluio antiético e imoral nas espúrias relações entre o procurador coordenador da Operação Lava-Jato e o ex-juiz da $13^{a}$ Vara de Curitiba e, atualmente, Ministro da Justiça do Governo Bolsonaro. Disponível em https://theintercept.com/2019/06/09/editorial-chats-telegram-lava-jatomorol. Acesso em 20 de agosto de 2019. 
"Entende-se por marxismo o conjunto das ideias, dos conceitos, das teses, das teorias, das propostas de metodologia científica e de estratégia política e, em geral, a concepção de mundo, da vida social e política, consideradas como um corpo homogêneo de proposições até constituir uma verdadeira e autêntica 'doutrina'que se podem deduzir das obras de Karl Marx e de Friedrich Engels" (1998, p.72).

Com base principalmente na teoria social, há três características importantes do marxismo: a) definição do modo de produção de uma sociedade; b) processos de mudança no desenvolver dessas sociedades c) análise sobre o capitalismo moderno ou o problema da transição. Essas três características não se apresentam como um bloco monolítico inerte no tempo, pelo contrário, destilam contradições e nuances que se interligam ditando a dinâmica do processo conceitual em análise (LYRA FILHO, 1983).

Sobre o primeiro ponto - a definição do modo de produção de uma sociedade - deve-se ter em conta os principais tipos de sociedade humana e sua sucessão histórica, em que se dá importância prioritariamente à estrutura econômica, ou "modo de produção" na determinação da forma completa da vida social. O modo de produção é definido em torno das forças produtivas e suas relações de produção.

Como nos relata Marx (2003, p.5) no prefácio da Contribuição à Crítica da Economia Política:

[...] na produção social da sua existência, os homens estabelecem relações determinadas, necessárias, independentes da sua vontade, relações de produção que correspondem a um determinado grau de desenvolvimento das forças produtivas materiais. O conjunto destas relações de produção constitui a estrutura econômica da sociedade, a base concreta sobre a qual se eleva uma superestrutura jurídica e política [...] (MARX, 2003, p.5).

A segunda característica da definição de marxismo - os processos de mudança no desenvolver das sociedades - caracteriza-se pela junção de dois processos inter-relacionados no que tange às 
mudanças de um tipo de sociedade para outro: um processo provocado pelo progresso da tecnologia e outro no qual as transformações sociais são resultados das lutas de classe, conceito este chave para a compreensão da análise marxista, pois, de acordo com Marx e Engels (2002), "A história de toda sociedade até nossos dias é a história da luta de classes" (2002, p.23).

E, por último, a terceira característica do conceito de marxismo - a análise sobre o capitalismo moderno ou o problema da transição - diz respeito à análise do capitalismo moderno especificamente sobre a transição para o socialismo, pois o capitalismo seria a forma final da especificidade de uma sociedade de classes, em que o conflito-chave entre burguesia e proletariado se intensificaria juntamente às contradições das crises econômicas podendo ocasionar na excepcionalidade da abertura de uma vaga revolucionária (ARCARY, 2004) que poderia resultar no modo de produção socialista, em que os proletários ${ }^{6}$, constituídos pelo conjunto de excluídos e explorados, seriam, finalmente, os protagonistas da história 7 .

Na visão marxista, a crítica da economia política não compreende apenas uma crítica das representações falsas, mas é, ao mesmo tempo, uma crítica das condições objetivas e subjetivas que produzem necessariamente essas representações. Sob este aspecto, a teoria econômica clássica também não é simplesmente falsa, mas sim um reflexo adequado dos fenômenos do modo capitalista de produção e de suas relações internas. O valor, o dinheiro, o lucro e a mais-valia

6 Neste artigo, utilizaremos o conceito de proletário como na definição feita por Marx (1885) "As camadas mais baixas da classe média - os pequenos comerciantes, donos de lojas e comerciantes aposentados em geral, os artesãos e os camponeses todos estes submergem gradualmente no proletariado, em parte porque seu diminuto capital não é suficiente para a escala na qual é conduzida a Indústria Moderna, e, portanto, afunda na competição com os grandes capitalistas, e em parte porque suas habilidades especializadas são tornadas sem valor pelos novos métodos de produção." (MARX, 1885, p. 492).

7 No socialismo ainda haveria classes - apesar do protagonismo dos proletários; também haveria divisão do trabalho por profissões, alguns elementos de uma economia de mercado e de direito burguês. Dessa forma, pontuamos que também o modo de produção socialista deveria ser uma transição para o modo de produção definitivo, ou seja, uma sociedade sem classes e sem Estado, uma sociedade comunista. 
são formas fenomenais necessárias desse modo de produção, que, portanto, só podem desaparecer junto com ele, assim como seus signos subjetivos de conformação social. (HARVEY, 2011).

Para o marxismo, entre as principais classes sociais em disputa, a única que poderia compreender e empunhar a bandeira da crítica da economia política de forma enérgica e revolucionária é o proletariado e, realmente, essa absorção é condição prévia à sua emancipação. Nesse sentido, há a afirmação de que há um obstáculo existencial que impede a classe capitalista ou, em termos clássicos, a classe burguesa de aceitar a teoria de Marx e, além disso, contraria-a com a utilização de todos os instrumentos possíveis para ignorá-la e refutá-la. Lênin trata dessa questão na sua obra "As três fontes" em que relata o seguinte:

A doutrina de Marx suscita em todo o mundo civilizado a maior hostilidade e o maior ódio de toda a ciência burguesa (tanto a oficial como a liberal), que vê no marxismo uma espécie de 'seita perniciosa'. E não se pode esperar outra atitude, pois numa sociedade baseada na luta de classes não pode haver ciência social 'imparcial'. De uma forma ou de outra, toda a ciência oficial e liberal defende a escravidão assalariada, enquanto o marxismo declarou uma guerra implacável a essa escravidão. Esperar que a ciência seja imparcial numa sociedade de escravidão assalariada seria uma ingenuidade tão pueril como esperar que os fabricantes sejam imparciais quanto à questão da conveniência de aumentar os salários dos operários diminuindo os lucros do capital (LÊNIN, 2001, p. 44).

A centenária Revolução Russa de 1917 - que instalou os bolcheviques $^{8}$ no poder - criou condições inteiramente novas para o desenvolvimento do pensamento marxista. O leninismo-trotskismo ${ }^{9} \mathrm{e}$,

8 Bolcheviques eram a ala majoritária do Partido Social-Democrata dos Trabalhadores Russos que capitanearam a Revolução Russa de 1917 sob liderança de Vladimir Lênin.

9 Corrente político-ideológica dos líderes bolcheviques da Revolução Russa: Vladimir Lênin, que atuou na liderança da Revolução de 1917 a 1924 (ano de sua morte) e León Trotsky, de 1917 até sua expulsão da União Soviética em 1929. 
principalmente, o stalinismo ${ }^{10}$ estabeleceram-se como uma ideologia oficial dogmática que adquiriu grande influência internacional com a fundação de partidos comunistas dentro do modelo soviético em outros países, enquanto o Partido Socialdemocrata alemão (SPD), profundamente dividido e enfraquecido em razão da guerra mundial e consequente derrota dos levantes revolucionários de 1918-19, perdeu, com esses fatos, seu antigo prestígio.

O marxismo soviético, que em seus primórdios oxigenou o sistema-mundo com ideais e práticas de democracia popular, estatização de setores econômicos estratégicos para a soberania do país, melhoria da condição de vida dos trabalhadores, como os maciços investimentos em saúde e educação, além de todo o potencial artístico e esportivo deu lugar, logo após a chegada de Stálin ao poder, à radicalização do totalitarismo burocrático engessando seu potencial difusor de ideias e práticas progressistas. Destarte, outras formas de marxismo foram pensadas e aplicadas pelo mundo, como o marxismo latino-americano, tendo a Revolução Cubana à frente, o marxismo ocidental, como França e Itália (nestes, principalmente no campo das ideias) e oriental/ asiático, com a Revolução Chinesa de Mao. (ANDERSON, 2004).

A ideologia marxista - que representava em seu auge anos 1970, em termos práticos, $30 \%$ do território e $35 \%$ da população mundial tentava unir a concepção do marxismo como sociologia científica com uma concepção de aspecto leninista, como consciência revolucionária em um partido de classe operária, embora, logicamente, tenham originado importantes diferenças entre os principais expoentes desse ponto de vista, tais como Korsch (2008), Lukács (2012) e Gramsci (1968).

Korsch (2008) afirmou que a principal tendência do materialismo histórico era de um método científico empírico e não somente uma abordagem filosófica. Gramsci (1968), ao elaborar conceitos de Estado e sociedade civil, alertou para muitos elementos que poderiam ser, e foram, incorporados a uma teoria sociológica. Já Lukács (2012) referiu-se autocriticamente a um cuidado que deveríamos

10 Corrente político-ideológica comandada por losif Stálin, líder máximo da União Soviética desde a morte de Lênin em 1924 até sua própria morte em 1953. 
ter para não cairmos numa espécie de messianismo revolucionário utópico, expressando, dessa forma, indagações quanto ao conteúdo e validade metodológica do tipo de marxismo proposto até então. Sendo assim, os primeiros textos de Korsch e Lukács, também ajudaram a promover outra corrente de pensamento marxista, com a criação do Instituto de Pesquisa Social de Frankfurt, em 1923, que mais tarde, nos anos 1960, floresceu na teoria crítica da Escola de Frankfurt, trazendo uma plêiade de grandes pensadores como Adorno, Horkheimer e Habermas.

Durante boa parte da segunda metade do século $X X$ o marxismo influenciou o pensamento ocidental em muitas áreas. Por exemplo, em Cambridge, na Inglaterra, Piero Sraffa, Joan Robinson e Maurice Dobb - conhecidos como o Círculo de Cambridge - deram continuidade a uma crítica marxista da economia política, na qual foram utilizados vários elementos da teoria neo-ricardiana ${ }^{11}$. Nos Estados Unidos, Paul Baran (1986) deu início a uma abordagem marxista crítica dos problemas do subdesenvolvimento e de desenvolvimento no Terceiro Mundo. O economista brasileiro Celso Furtado também se destacou nas décadas de 1950-60 fazendo esta mesma abordagem, mesclando Marx e Keynes, principalmente quando era quadro técnico da CEPAL - Comissão Econômica para a América Latina e Caribe.

Algumas dessas contribuições ocidentais foram criticadas pelos marxistas ortodoxos, cujas obras, porém, desde a morte de Lênin e com raras exceções, não foram marcadas por nenhuma realização notável. Se a filosofia e a teoria social soviética realizaram qualquer progresso, isto ocorreu a respeito do, e não com base no, marxismo soviético, e sobretudo em campos altamente especializados como a lógica matemática e a cibernética, que também apresentaram aplicações tecnológicas, inclusive militares, muito substanciais. Uma das principais razões da vitalidade do pensamento marxista é, sem dúvida, o fato dele ter permanecido aberto para outros avanços, não-marxistas, nas ciências sociais, na filosofia e em outras disciplinas, como

11 Entende-se por neo-ricardiano os adeptos da teoria econômica de David Ricardo (17721883), em que se valoriza o trabalho como fonte de todo o valor de troca e que considerava o lucro e os juros como distorções do mercado livre. 
atestou Lyra Filho (1983): “...ideias nas quais, precisamente, à falta de articulação sistemática, fervilham as ambiguidades, antinomias e extrapolações temerárias". (1983, p.52).

Com uma polêmica trajetória ao longo da história e mesmo com contratempos paradigmáticos como a queda do muro de Berlim, o fim da Guerra Fria e do chamado "socialismo real" é de se admirar que o marxismo, em pleno século XXI, continue influente e revigorante, seja nas universidades, nos partidos políticos de esquerda, nos sindicatos, nos movimentos sociais, na institucionalidade e em outros ambientes; o que prova que a questão temporal não é relevante para medirmos o grau de suposta modernidade e desenvolvimento dos povos, mas, sim, a sua condição material de existência. Como escreveu Benjamin (2000):

O capitalismo venceu. Talvez, agora, possa perder. Pois, antes que o novo tenha condições de surgir, Hegel dizia, é preciso que o antigo atinja a sua forma mais plena, que é também a mais simples e mais essencial, abandonando as mediações de que necessitou para se desenvolver. $O$ momento do auge de um sistema, quando suas potencialidades desabrocham plenamente, é o momento que antecede seu esgotamento e sua superação. As crises do mundo contemporâneo mostram que a acumulação de capital e a forma-mercadoria não podem mais ser o princípio organizador da vida social. É o desafio que está posto para nós neste século (XXI). O pensamento de Marx nunca esteve tão vivo (BENJAMIN, 2000, p. 58).

A importância do marxismo na atualidade ganha força com a conjuntura política em que vivemos e com seus impasses em torno da desigualdade social, concentração de renda, crise dos refugiados e imigrantes, crise econômica do capitalismo financeiro e fenômenos que estão pautando nossa agenda de lutas, como o feminismo, LGTBI's, o movimento negro, a luta contra a nova direita, entre outros pontos cruciais da atualidade.

Depois dessa brevíssima explanação sobre o marxismo, discorreremos sobre o objeto principal de nosso trabalho: a pedagogia marxista e suas principais características. 


\subsection{A PEDAGOGIA MARXISTA}

Na segunda metade do século XIX começaram a surgir elementos de uma concepção marxista de educação, fato comprovado em muitas obras de Marx e Engels como, por exemplo, O Capital (1867) e Crítica ao Programa de Gotha (1891).

Essas obras foram utilizadas por militantes e estudiosos da educação que posteriormente formularam uma teoria mais coerente e sistematizada sobre o que podemos denominar de educação marxista. Grande impulso para que isto ocorresse foi dado pela Revolução Russa de 1917 - Revolução de Outubro - ocasião em que o partido bolchevique, capitaneado por Lênin, toma o poder e aplica a prática pedagógica do "novo homem" em todo o continente russo.

Lênin defendia a teoria marxista da educação como, essencialmente, uma teoria da prática. Pensava a formação dos cidadãos para a incipiente sociedade socialista: que soubessem comandar e se subordinar aos seus companheiros, que fossem trabalhadores e cultos. Para que atingisse esse intuito, o Estado soviético deveria investir solidamente em educação e instrução.

Relataremos, a seguir, de forma breve e sucinta, as ideias de alguns dos principais educadores marxista-leninistas que participaram da construção educacional da Revolução Russa: Makarenko, Lunatcharski, Vygotsky, Krupskaia e Pistrak, abordando suas principais colaborações e contribuições.

\subsubsection{ANTON SEMIONOVICH MAKARENKO (1888-1939)}

Pedagogo e escritor de origem ucraniana, Makarenko educou crianças marginalizadas na Colônia Gorki (1920-1928) e na Comuna Dzerjinski (1927-1935) na então União Soviética - URSS.

Defendia como objeto da educação a coletividade escolar e não mais a criança isolada; advogava pela tese da criança em constante relação com seu mundo concreto e objetivo - diferentes crianças com suas 
marcas históricas, sociais, culturais e psicológicas, uma educação das diferentes personalidades, contrapondo à tese da criança "abstrata", esta como se fosse um ideal a ser alcançado. (MAKARENKO, 2012).

A escola idealizada e organizada por Makarenko tinha em sua concepção um espaço amplo e aberto em contato permanente com a sociedade, participando dos problemas sociais da população, além da preservação e conscientização ambiental. A orientação era de que todos devessem seguir o objetivo traçado coletivamente por professores e alunos, sem hierarquia, relacionando-o às necessidades sociais de cada momento histórico numa constituição dialética da coletividade, o que significava planejar, racionalmente, os passos para o funcionamento do que se denominava autogestão.

Na Colônia Gorki (1920-1928), que objetivava a ressocialização de centenas de crianças e jovens que viviam sob estado de pobreza e violência, formaram um Conselho Pedagógico com o escopo de instituir normas disciplinares, uma espécie de tribunal democrático-escolar, em que se convocava uma Assembleia Geral para julgar casos de indisciplina - e também onde poderiam organizar coletivos para específicas atividades como finanças, cultura, esporte, entre outros; a preocupação essencial da Colônia era a junção entre o trabalho e o estudo (MAKARENKO, 2012).

$\mathrm{Na}$ Colônia se praticava uma disciplina que poderia ser considerada até certo ponto militar, com destacamentos para ocupações de estrada com o objetivo de proteger a vizinhança de pequenos delitos e até mesmo ocupação de terras improdutivas para o cultivo de horta coletiva, os estudantes uniformizados formavam fileiras de tropas marcadas pelo ritmo de cornetas e tambores que marchavam com bandeiras em punho e entoavam cantos e gritos de guerra. Isso demonstrava um aspecto de pertencimento a uma coletividade, o que fortalecia os laços de solidariedade entre os jovens (MAKARENKO, 2012).

Toda a experiência emancipadora e libertária que discorremos na Colônia Gorki sofreu um abalo considerável com a chegada de Stálin ao poder na União Soviética. Na Comuna Dzerjinski (1927-1935) em Kharkov, onde existiam mais de cem colonos, foi implementado o plano 
de industrialização de Stalin e que Makarenko foi o responsável pela implementação do trabalho monotécnico baseado no taylorismo ${ }^{12} \mathrm{e}$ no fordismo ${ }^{13}$, de maneira que os educandos não obtivessem um conhecimento amplo do modo de produção, restringindo-se apenas às necessidades do aumento da produtividade para obedecer as normas do Estado Soviético (LUEDEMAN, 2005).

\subsubsection{ANATOLI VASILEVITCH LUNATCHARSKI (1875-1933)}

Educador russo, além de dramaturgo e crítico literário, foi Comissário do $\mathrm{Povo}^{14}$ para a cultura e educação no primeiro governo da URSS até o ano de 1929.

Lunatcharski defendia a eleição direta dos professores pela própria comunidade, que era organizada em comitês e que poderia assumir certa influência no direcionamento da escola. Os professores, assim como os membros do comitê da região escolar, seriam incentivados a prestarem contas de suas ações para o desenvolvimento pedagógico perante à comunidade, numa atitude de transparência e compromisso com a gestão democrático-escolar.

$\mathrm{Na}$ condição de Comissário do Estado soviético, Lunatcharski liquidou os restos do antigo aparelho czarista, suprimiu a função de procuradores dos distritos e de diretores e inspetores da escola - pois poderiam ser considerados pela comunidade como instrumentos de constrangimento e censura - proibiu o ensino do catecismo em respeito ao Estado laico e introduziu o ensino misto com participação de ambos os gêneros no convívio escolar (LUNATCHARSKI, 2002).

12 Taylorismo era uma teoria baseada na forma de controle da linha de produção em que se enfatizava o máximo de exploração do rendimento de cada trabalhador. Tinha esse nome pois foi concebido por Frederick Taylor (1856-1915).

13 O Fordismo foi a aplicação prática do taylorismo nas fábricas, e também se caracterizava por ser um sistema de produção em massa que visava explorar o máximo de mais-valia de cada trabalhador. Tinha esse nome pois foi criado por Henry Ford (1863-1947).

14 Comparando a forma institucional, Comissário do Povo na União Soviética seria o mesmo que Ministro de Estado nos países do Ocidente. 
O Ministro da Educação soviética defendia ainda a "escola do trabalho" como modelo pedagógico, em que o trabalho seria matéria de estudo, isto é, como ensino de técnica em seu conjunto. Esse trabalho teria a marca da coletividade, pois baseado na autogestão cooperativa.

Diferentemente de Makarenko, e aproveitando-se de um nível mais aberto de conjuntura política, orientou às escolas ao trabalho politécnico onde os jovens e adultos aprenderiam diversas técnicas como agricultura, marcenaria, contabilidade, entre outras atividades importantes para o educando e também para a sociedade em que fazia parte como indivíduo.

Além disso, defendia a "educação estética" - na qual a tarefa fundamental do ser humano seria a de tornar belo a si mesmo e a tudo o que o rodeia - ligada à técnica e à física. Os jovens educandos, seguindo essa orientação, tinham plena liberdade na organização das sociedades consagradas às ciências, à ginástica, à música, ao teatro, na criação de revistas e de clubes políticos, aliando, dessa maneira, a prática cultural e de esportes como valor cotidiano (LUNATCHARSKI, 2002).

Também sedimentou a ideia de que os professores não deveriam, em hipótese alguma, inculcar nas crianças uma espécie de doutrinação forçada sobre o aprendizado da ideologia socialista, sendo que com o passar do tempo as próprias crianças adquiri-la-iam naturalmente.

Lunatcharski ainda estabeleceu um plano de educação para os adultos que envolvia alfabetização plena ${ }^{15}$, intensificação nos ensinos primário e secundário, criação de uma Faculdade Operária (Rabfak) com incentivo à instrução extraescolar na criação e permanência de cinemas, apresentações teatrais e bibliotecas, todos com entrada gratuita, tornando o local universitário um projeto bem definido de extensão (LUNATCHARSKI, 2002).

Por fim, Lunatcharski também é lembrado como defensor da denominada "escola única", denominação que representava a típica escola

15 No Império Russo pré-revolução não havia um sistema nacional de ensino até o final do século XIX e início do século XX: $71 \%$ dos homens e $87 \%$ das mulheres eram analfabetas, sendo um grande desafio para a Revolução Bolchevique. (Rosenberg, 1989). 
do socialismo onde estudariam todas as classes sociais - proletários, camponeses, profissionais liberais ou filhos destes - utilizando-se os mesmos métodos de ensino, observando o máximo de respeito possível entre os integrantes do neófito e desafiante Estado soviético.

\subsubsection{LEV SEMENOVICH VYGOTSKY (1896-1934)}

Psicólogo e pedagogo russo, trabalhou no Instituto de Psicologia de Moscou, sendo proponente da Psicologia cultural-histórica ${ }^{16}$. Vygotsky observava que a diferença entre educador e educando deveria ser bem delimitada para a conjunção dialética entre os saberes, vital para o aprendizado educacional.

A diferença entre saber e não saber não pode estar tão próxima que permita ao educando agir sozinho, pois já infere que sabe e assim não há nada a aprender. $\mathrm{E}$ nem tão distante que impeça o educando de agir, por não o conseguir fazer. É importante a interação de algo, como um cenário, ou de alguém, que estimule o educando através de desafios que possam ser superados, paulatinamente (VYGOTSKY, 2008).

A produção de um ambiente educativo parte da premissa de que nada deve acontecer por acaso ou sem intencionalidade pedagógica. Foi assim que Vygotsky formulou seu conceito de Zonas de Desenvolvimento que poderiam apresentar três patamares: Real, Potencial e Proximal (CAIXETA et al. 2015).

A Zona de Desenvolvimento Real acontece quando as etapas são alcançadas e consolidadas pelo educando, isto é, quando findo o processo educacional o educando cumprir a tarefa proposta sem nenhum tipo de auxílio, estando plenamente apto.

A Zona de Desenvolvimento Potencial acontece quando o educando realiza a tarefa, mas ainda necessitando de auxílio de outro educando/ educador, estando potencialmente apto para a execução da tarefa.

16 Tipo de aprendizado em que a psicologia "natural", mais quantitativa, fosse ligada à psicologia "mental", mais subjetiva. 
Já a Zona de Desenvolvimento Proximal é a distância entre as duas anteriores - Real e Potencial - em que o educando consegue realizar a tarefa percebendo apenas as motivações do meio, que, como afirmamos, pode ser um cenário ou pessoa.

Vygotsky dava importância a este "meio" como ambiente educativo onde se desenvolvia o chamado materialismo psicológico - baseado no materialismo dialético - em que se afirmava que a consciência procede da experiência, tem um caráter secundário e depende, psicologicamente, do meio. Parafraseando, então, Marx e Engels, que sustentava que "a experiência determina a consciência".

Lev Vygotsky faleceu em 1934 com apenas 37 anos de idade e suas ideias à época não foram bem recebidas pela burocracia soviética, quase que caindo no esquecimento, sendo reabilitadas anos depois de sua morte por educadores ocidentais seguindo até a atualidade como grande inspiração pedagógica para os educadores de todo o mundo.

\subsubsection{NADEZHDA KONSTANTINOVNA KRUPSKAIA (1869-1939)}

Revolucionária e educadora russa, foi Vice-Comissária do Povo para a cultura e educação, trabalhando juntamente com Lunatcharski.

Krupskaia obtinha todas as condições para assumir qualquer cargo de alto escalão no governo soviético, pois era dotada de rígida formação intelectual e era uma das principais revolucionárias, sendo destacada combatente dos bolcheviques; mas, pela conjuntura ainda machista e patriarcal dos revolucionários russos, foi escolhida para ser Vice-Comissária do Povo, uma espécie de Secretária Executiva do Ministério ${ }^{17}$, se formos comparar com a estrutura burocrática brasileira atual. Ainda hoje, muitos se referem a Krupskaia como apenas "a muIher de Lênin"18, uma flagrante injustiça frente a seus grandes feitos.

17 A "número 2" do Ministério, abaixo do Ministro.

18 Casou-se com Lênin em 1898 e o acompanhou até sua morte (1924). 
A pedagoga russa Krupskaia foi a principal idealizadora na luta contra o analfabetismo soviético, entregando-se com afinco para o cumprimento do decreto governamental de 1919 que determinava iniciativas para a eliminação do analfabetismo entre os habitantes de 8 a 50 anos em todo o território nacional.

Krupskaia era a referência intelectual e militante da Comissão Extraordinária para a Eliminação do Analfabetismo, criada em 1920 e que conseguiu reunir jovens estudantes, professores e intelectuais com o objetivo de obter êxito nesse intento. Entre 1920 e 1940 os resultados vieram, aproximadamente 60 milhões de cidadãos foram alfabetizados, enquanto a imensa maioria dos jovens foi escolarizada, um empreendimento de sucesso que fez a justa fama de Krupskaia como uma das maiores educadoras do país. (KRUPSKAIA, 2017).

Depois do êxito alcançado pela erradicação do analfabetismo, Krupskaia empreendeu esforços para unir o ensino básico - ler, escrever e contar - ao sofisticado ensino das ciências naturais e sociais para que fossem compreendidos: a) uma visão materialista dos fenômenos naturais e o uso racional das forças da natureza; b) uma visão de compreensão de relações de classe e de desenvolvimento social.

Krupskaia lutou também pela emancipação feminina, ao pautar escolas e postos de trabalho com o objetivo de implementar creches que atendessem a demanda das mães e das chefas de família. Sua intransigente defesa a favor de um ensino politécnico, concatenando a teoria à prática, a escola à vida, com destaque para a iniciação profissional, a autogestão pedagógica, a ligação entre família e coletividade, assim como suas ressalvas e críticas à educação tradicional, são até os dias hodiernos reconhecidas como referencial para educadores da Rússia do século XXI e de vários países do mundo ocidental.

Dessa maneira, Krupskaia também é lembrada como militante de destaque do Partido Bolchevique, sendo que suas concepções sobre educação influenciaram a implementação de novos métodos e práticas de ensino da URSS, tendo sido também uma das organizadoras do sistema bibliotecário soviético, além de coordenadora do Comitê Principal para Educação Política - "Glavpoliprosvet". 
Krupskaia faleceu no ano de 1939, aos 70 anos de idade, sendo homenageada por todo o povo soviético e recebendo o reconhecimento máximo de sua trajetória ao ser sepultada na necrópole da muralha do Kremlin, junto a influentes personalidades que moldaram o país.

\subsubsection{MOISEY MIKHAYLOVICH PISTRAK (1888-1940)}

Educador russo e também um dos principais formuladores da $\mathrm{Pe}-$ dagogia soviética pós-Revolução de 1917. Foi criador e grande entusiasta da chamada "Escola do Trabalho" ideia que compreendia o trabalho como a atividade específica do ser humano, orientada para a transformação da natureza, auxiliado por instrumentos de trabalho, para que assim pudesse satisfazer suas necessidades, mas que, ao transformar a natureza, transformava a si mesmo, à sua atitude frente a natureza, frente aos outros a si mesmo, aprofundando suas ideias e sua possibilidade de conhecer e transformar a realidade. Defende assim a reflexão no momento do trabalho sobre o que se faz e como se faz para que possa, dessa maneira, produzir sujeitos sociais e culturais (PISTRAK, 2008).

Pistrak, em acordo com a maioria dos pedagogos soviéticos citados neste trabalho, defendia, dessa forma, a transformação dialética da educação, com valores de ensino formal e revolucionário, atinentes aos ideários da Revolução Russa.

Assim como os demais educadores, trabalhava sob pressão dos acontecimentos da Revolução soviética, e sob a responsabilidade de sucesso da primeira experiência socialista no âmbito político, econômico e educacional, o que justificava a prioridade dada pelo autor ao trabalho industrial. O trabalho na fábrica incluía o complexo de relações sociais de produção e isto propiciava a observação de preceitos importantes para ele, devido a isto Pistrak elaborara um ambiente escolar condizente com o da fábrica, seguindo seus traços e características (TRAGTENBERG, 1981).

Demonstramos, assim, em apertada síntese, as principais ideias de pedagogos russos/soviéticos pós-Revolução de 1917. Vimos que 
enquanto vigorava a liderança da dupla Lênin-Trotsky havia certa oxigenação das práticas educadoras, com muita pesquisa, ensino e aspectos de uma pedagogia de extensão que envolvia a comunidade, sempre sob a égide da dialética.

\subsection{RELAÇÃO ENTRE A PEDAGOGIA MARXISTA E O ENSINO JURÍDICO BRASILEIRO}

O nosso desafio é fazer com que o atual ensino jurídico brasileiro possa ser minimamente influenciado pelos educadores marxistas supramencionados, como, por exemplo, nos seguintes procedimentos de ensino: - importância da teoria aliada à prática, mas teoria aqui em um sentido crítico, que iria além do positivismo-legalista-formal com o intuito de inserir o Direito na realidade dos hipossuficientes para que estes sejam cidadãos questionadores e sabedores de seus direitos; flexibilidade hierárquica horizontal entre os estudantes e professores, desprovidos de vaidades e incutindo maior responsabilidade ao alunato; - projetos de ensino, pesquisa e extensão atinentes com as causas da população carente, debatendo e transformando a realidade de um país como o nosso de imensa desigualdade social; - pensar em um projeto de país soberano, preservando iniciativas de participação democrática da gestão pública, em consonância com a luta por um poder judiciário transparente e compromissado com o Brasil.

O pluralismo dialético representado pelos pedagogos marxistas contribuiu significativamente na formação de uma teoria jurídica crítica em nosso país que, segundo Wolkmer $(2009$, p.5) seria conceituada como um:

[...] instrumental pedagógico operante (teórico-prático) que permite a sujeitos inertes e mitificados uma tomada histórica de consciência, desencadeando processos que conduzem à formação de agentes sociais possuidores de uma concepção de mundo racionalizada, antidogmática, participativa e transformadora. Trata-se de proposta que não parte de abstrações, de um a priori dado, da elaboração mental pura e simples, mas da 
experiência histórico-concreta, da prática cotidiana insurgente, dos conflitos e das interações sociais e das necessidades humanas essenciais. (WOLKMER, 2009, p.5).

Veremos, a seguir, que a pedagogia marxista aqui sistematizada serviu de parâmetro para experiências de teoria jurídica crítica, como na pedagogia do MST e seus formandos em Direito da Terra e também no movimento do Direito Achado na Rua, capitaneado por Roberto Lyra Filho, influenciando na educação jurídica de seus sujeitos políticos.

\section{A PEDAGOGIA DO MOVIMENTO DOS TRABALHADORES RURAIS SEM TERRA - MST}

Desde julho de 1987, na cidade de São Mateus (ES), onde aconteceu o $1^{\circ}$ Encontro Nacional de Professores de Assentamentos, o MST constituiu um setor específico para tratar dos desafios ligados à questão do direito à educação dos trabalhadores rurais sem terra ${ }^{19}$.

Segundo o MST, este setor está organizado em 24 Estados brasileiros, formando um universo de milhares de escolas públicas construídas em acampamentos e assentamentos, nos quais mais de duzentos mil crianças, adolescentes, jovens e adultos estariam regularmente frequentando.

Trabalhando diretamente com essas escolas são cerca de quatro mil educadores, incluindo os que atuam nas Cirandas Infantis até em cursos superiores em parceria com universidades públicas. $\mathrm{O}$ Movimento mobiliza ainda milhares de educadores na alfabetização de jovens e adultos, totalizando hoje aproximadamente 100 mil adultos alfabetizados ${ }^{20}$.

19 O setor de educação do MST completou 30 anos em 2017, sendo comemorados com a formação da sua $5^{\text {a }}$ Turma do Curso Nacional de Pedagogia, na mesma cidade de São Mateus, norte do Espírito Santo. Disponível em http://www.mst.org.br/2017/01/30/ mst-celebra-30-anos-do-setor-educacao-realizando-5a-turma-do-curso-nacional-depedagogia-no-estado.html Acesso em 19 de agosto de 2019.

Disponível em http://www.mst.org.br/educacao/ Acesso em 19 de agosto de 2019. 
Baseado nos estudos de Caldart (2005), enumeramos as principais características da pedagogia do MST a nível nacional, que continuam em vigor até os dias de hoje nas lonas da cidadania pelo país afora:

3.1.1) Para a educação infantil há as chamadas "Cirandas Infantis", onde os educadores organizam o conjunto de trabalho que vão desde o período de gestação dos bebês até atividades com os pais, num ambiente de fortalecimento de vínculos. As crianças são estimuladas a participarem de brincadeiras, jogos, ouvem músicas, assistem filmes recreativos e participam até mesmo de mini-marchas, denominadas de "Marcha dos Sem Terrinha"21;

3.1.2) Para o ensino fundamental e médio, os educadores organizam várias reuniões com os assentados/acampados, juntamente com seus filhos, a comunidade e também, a depender da demanda, com o secretário de educação do município ou do Estado para que possam organizar a escola a partir das necessidades locais e coletivas, buscando a criação de um currículo que atenda às necessidades do campo. Todas essas escolas do MST são públicas e a maioria é reconhecida pelos Conselhos Municipais e Estaduais de Educação e pelo MEC (Ministério da Educação);

3.1.3) Para o ensino superior, a partir de 1998, o MST começou a fazer parcerias com universidades para a implementação do curso superior de Pedagogia - Pedagogia da Terra - com currículo voltado para o meio rural, contendo matérias sobre produção, história do campo, método de aprendizagem com ferramentas de trabalho, entre outras; tendo em vista a formação de professores - em sua maioria os próprios acampados/assentados. Sublinha-se que a maioria desses cursos foram procedimentalmente aprovados pelo MEC;22

3.1.4) A organização da escola segue orientação do Conselho Pedagógico, apresentando como lastro epistemológico as diretrizes do Co-

21 Entre os dias 23 e 26 de julho de 2018, aconteceu o $1^{\circ}$ Encontro Nacional das Crianças Sem Terrinha, em Brasília/DF. Disponível em http://www.mst.org.br/sem-terrinha/ Acesso em 19 de agosto de 2019.

22 Disponível em http://portal.mec.gov.br/projovem-campo--saberes-da-terra Acesso em 19 de agosto de 2019. 
letivo Nacional de Educação do MST - instância do setor de educação. Os alunos são divididos em núcleos que geralmente são batizados com nomes de trabalhadores que tombaram na luta pela terra. Cada núcleo tem um grito de guerra característico, há um revezamento entre eles no que concerne as atividades do dia-a-dia: jardinagem, limpeza, alimentação, organização do estudo; além de conter uma gestão democrática em que os membros dos núcleos têm direito a opinar e a decidir sobre os rumos da escola;

3.1.5) A ocupação de terras, as fileiras organizadas na "Marcha dos Sem Terra", as bandeiras, as músicas, os gritos de guerra, as fotos de revolucionários, as apresentações teatrais - místicas - são consideradas matrizes não só organizativas do MST, mas fundamentalmente estímulos pedagógicos, implicando na compreensão do Movimento como lugar de formação de sujeitos sociais;

3.1.6) A coletividade consubstancia-se em trabalho de auto-organização da escola com o intuito de preservá-la, além de haver capacitação junto à aprendizagem do trabalho, em especial o trabalho cooperativo. Incentiva-se processos educativos interagindo com processos políticos e econômicos, em que a realidade apresenta-se como base da produção do conhecimento tendo como relação contínua a interação entre teoria e prática;

3.1.7) Luta contra o analfabetismo, devido ao grande número de analfabetos que ainda persistem no meio rural brasileiro. A cooperação do MST nessa batalha já rendeu frutos importantes, não só pela alfabetização de uma estimativa de aproximadamente cem mil assentados e acampados como o reconhecimento de organizações internacionais que premiaram essa iniciativa do Movimento ${ }^{23}$.

É bom ressaltar que por ser tratar de um Movimento nacional que cobre 24 Estados de um país continental como o nosso, es-

23 A nível nacional, não se tem o número exato de quantos trabalhadores rurais sem-terra foram alfabetizados pelo Movimento ao longo dos mais de 30 anos do setor de educação da entidade; mas sabe-se que o projeto cubano do "Sim, eu posso" está sendo aplicado de forma eficiente em vários estados brasileiros sob a liderança do MST. Disponível em https://www.brasildefato.com.br/2018/02/07/metodo-cubano-ja-alfabetizou-35-milhoesde-pessoas-na-america-latina-e-na-africal Acesso em 20 de agosto de 2019. 
sas características aqui elencadas não são homogêneas, havendo unidades federativas que estão mais à frente nesse processo educacional e outras que ainda estão em formação de estruturas e conquistas mínimas para a efetivação desse direito humano à educação e ao pensamento crítico.

Constatamos que a pedagogia aplicada pelo MST se assemelha bastante à pedagogia marxista dos educadores soviéticos, pois há relação dialética entre estudo e trabalho, participação da comunidade, estímulos de cenários como na educação estética, auto-organização cooperativa, luta pela erradicação do analfabetismo, importância da formação de novos cidadãos com responsabilidade de ação e teoria, entre outros aspectos relacionais.

\subsection{A RELAÇÃO ENTRE A PEDAGOGIA DO MST E O ENSINO JURÍDICO BRASILEIRO}

A Pedagogia do MST tem influenciado o ensino jurídico brasileiro por meio dos cursos denominados de "Direito da Terra", cursos de Direito em que são formados assentados da Reforma Agrária por meio do Pronera (Programa Nacional de Educação da Reforma Agrária), criado em $1998^{24}$, com apoio do Incra (Instituto Nacional de Colonização e Reforma Agrária). ${ }^{25}$

Atualmente, há 142 estudantes de Direito do meio rural que estudam em parceria com três universidades federais no Brasil - Universidade Federal de Goiás (UFG), Universidade Federal do Paraná (UFPR) e Universidade Federal do Sul e Sudeste do Pará (Unifesspa) - além de outros 137 estudantes que já se formaram em Direito da Terra na UFG (2012), Universidade do Estado da Bahia (UNEB/2017) e Universidade

24 Atualmente, o Pronera é regido pelo Decreto $n^{\circ} 7.352$, de 4 de novembro de 2010 que "Dispõe sobre a política de educação do campo e o Programa Nacional de Educação na Reforma Agrária - PRONERA. Disponível em http://portal.mec.gov.br/docman/ marco-2012-pdf/10199-8-decreto-7352-de4-de-novembro-de-2010/file. Acesso em 19 de agosto de 2019.

25 Disponível em http://www.incra.gov.br/educacao pronera. Acesso em 19 de agosto de 2019. 
Estadual de Feira de Santana (UEFS/2018). Portanto, até o momento, são 6 turmas de Direito da Terra.

As principais contribuições do Direito da Terra baseadas na Pedagogia do MST para a teoria crítica do Direito no Brasil são as seguintes: - análise aprofundada sobre a função social da propriedade e debate sobre a concentração de terras, renda e propriedades em nosso país; - sistematização sobre o desenvolvimento de um Direito Agrário, com respeito à Terra em suas várias diretrizes, tais como alimento, solo, água, além de Direito sobre os Povos Indígenas e Tribais; - a conciliação entre o tempo-universidade com o tempo-comunidade, pois, segundo o professor da UFPR, Caetano, "É um compromisso de férias de todos eles realizar atividades complementares nas comunidades, portanto eles estudam o ano todo". ${ }^{26}$

Até o ano de 2016, o Pronera havia formado mais de 190 mil alunos de áreas de Reforma Agrária no Brasil, em mais de 500 cursos oferecidos, sendo aproximadamente 170 mil formados pela Educação de Jovens e Adultos (EJA), 9 mil formados no nível médio e mais de 5 mil alunos que concluíram o ensino superior, além de 1.765 especialistas com pós-graduação, segundo dados do INCRA. ${ }^{27}$

\section{A PEDAGOGIA DE ROBERTO LYRA FILHO E O DIREITO ACHADO NA RUA}

Dialogando com as perspectivas pedagógicas apresentadas anteriormente, tanto em relação à pedagogia marxista quanto à pedagogia do MST, apresentaremos a atuação político-pedagógica do Direito Achado na Rua, que possui como referência fundadora o jurista Roberto Lyra Filho, expoente da teoria crítica do Direito no Brasil.

Destacando a origem e atuação da Nova Escola Jurídica Brasileira (NAIR), liderada por Roberto Lyra Filho, José Geraldo de Sou-

26 Disponível em http://www.mst.org.br/2019/02/06/turma-de-direito-do-pronera-seformara-em-2019.html. Acesso em 19 de agosto de 2019.

27 Disponível em http://www.incra.gov.br/noticias/pronera-21-anos-formando-jovens-eadultos-para-o-desenvolvimento-do-campo. Acesso em 19 de agosto de 2019. 
sa Júnior (2015) enumera três elementos norteadores do Direito Achado na Rua, a saber:

“1) Determinar o espaço político no qual se desenvolvem as práticas sociais que enunciam direitos, a partir mesmo de sua constituição extralegal, como por exemplo, os direitos humanos; 2) Definir a natureza jurídica do sujeito coletivo capaz de elaborar um projeto político de transformação social e elaborar a sua representação teórica como sujeito coletivo de direito; e 3) Enquadrar os dados derivados destas práticas sociais criadoras de direitos e estabelecer novas categorias jurídicas para estruturar as relações solidárias de uma sociedade alternativa em que sejam superadas as condições de espoliação e de opressão entre as pessoas e na qual o direito possa realizar-se como um projeto de legítima organização social da liberdade". (SOUSA JÚNIOR, 2015, p.3).

Esses três elementos norteadores deveriam estar marcados na formação jurídica dos ativistas do Direito brasileiro. A crítica sistemática em relação à fixação pela norma, numa espécie de fetichismo jurídico, em que o estudante de Direito estaria preso a uma interpretação positivista-legalista seria um passo importante para a democratização do ensino jurídico brasileiro. Tanto nos departamentos de Direito de várias faculdades pelo país, como principalmente na fábrica de cursinhos jurídicos, há um apego desproporcional às normas jurídicas e também às jurisprudências dos tribunais superiores, num "decoreba" acrítico e monótono extirpando qualquer potencial de crítica construtiva e transformação social.

Infelizmente, a constatação é a de que a formação do jurista brasileiro está condizente com a classificação de Althusser (1983) que denominava o Direito como Aparelho Ideológico e Repressivo do Estado (AIRE), servindo como lastro justificador para a manutenção do sistema capitalista em sua produção e reprodução do capital. São, em sua maioria, juristas desprovidos de senso crítico e de qualquer aspecto de solidariedade, pensamento de nação e protagonismo político libertador, apenas repetidores das normas engendradas pelos poderosos de sempre, nem que para isso precise distorcer consciente 
e repetidamente o sistema de precedentes brasileiro causando sistematicamente relevante insegurança jurídica.

Quando observamos, na maioria das vezes, uma sala de aula com futuros juristas, seja esta em uma Faculdade, em um centro de ensino ou em um cursinho jurídico, é irresistível não lembrarmos da música "Another brick in the wall", da banda britânica Pink Floyd (1979), em que a formação aplicada nas salas de aula se destina a moldar apenas "cabeças-tijolo", num mesmo muro de aceitação e conformismo. Como relatou Lamounier $(2018)^{28}$, citando o exemplo específico de advogados, mas que serve para todas as carreiras jurídicas:

"Como grupo, os advogados não meditam muito sobre esses temas institucionais, sobre as premissas filosóficas da carreira. Acho até que eles não leram muito e a grande maioria dos cursos de Direito parece não ter boa qualidade. O nível de leitura é muito prático, voltado aos códigos e à letra da lei". (LAMOUNIER, 2018).

Os três elementos norteadores da Nova Escola Jurídica Brasileira (NAIR) - que citamos acima - são um contraponto imprescindível para a transformação do ensino jurídico brasileiro, para que se tente evitar a formação de "cabeças-tijolo".

Sousa Júnior (2015) destaca também as quinze proposições elaboradas por Lyra Filho em relação ao posicionamento da NAIR, sendo as primeiras cinco proposições com sentido negativo, ou seja, sobre o que a NAIR não seria caracterizada:

“a) não tomamos a norma pelo Direito; b) não definimos a norma pela sanção; c) não reconhecemos apenas ao Estado o poder de normar e sancionar; d) não nos curvamos ante o fetichismo do chamado direito positivo, seja ele costumeiro ou legal; e) não fazemos do Direito um elenco de restrições à liberdade, como se esta fosse algo a deduzir a contrario sensu do que sobra, depois de sancionado o furor criativo de ilicitudes, quer pelo Es-

28 Disponível em https://www.conjur.com.br/2018-ago-04/entrevista-bolivar-lamouniersociologo-cientista-politico Acesso em 19 de agosto de 2019. 
tado quer pelos micro-organismos concorrentes, que estabelecem o poder social dividido (o chamado poder dual)". (SOUSA JÚNIOR, 2015, p. 68).

Para contrapô-las são apresentadas mais cinco proposições, desta vez proposições positivas, ou seja, esclarecendo afirmativamente quais seriam as principais características da NAIR:

“a) que o Direito é, antes de tudo, liberdade militante; b) que a justiça histórica e concreta não se determina senão pelo estabelecimento gradual de porções crescentes de liberdade conscientizada; c) que o padrão de legitimidade, na concorrência das normas, está no vetor histórico, donde se extrai a resultante mais avançada duma correlação de forças, em que se torna reconhecível a vanguarda, marca-se o posicionamento progressista e atua-se para garantir as suas reivindicações, tratando de exprimir o sumo e o extrato do processo libertador a que se dá o nome de Direitos Humanos; d) que o processo mesmo de libertação nem pode desconhecer os seus limites jurídicos, nem deferir a tutores a determinação exclusiva e concreta do círculo de liberdade de cada um; e) que a positivação dialética do Direito, isto é, a sua efetivação gradual e em luta na totalidade histórica em movimento, mediante a qual se esclarecem, concretizam e polarizam, como Direitos reclamados, os aspectos concretos do Direito geral de libertação, jamais toleram que aquela positivação seja acorrentada numa ordem social e seu suposto 'direito positivo"” (SOUSA JÚNIOR, 2015, p. 68-70).

Da mesma forma, importante salientar os referenciais teóricos da NAIR - hegelianismo, marxismo, pós-marxismo - a sistematização da categoria jurídica do humanismo dialético, o sumário do Direito Achado na Rua elaborado por Lyra Filho, o destaque para o que significava o termo "rua" como "metáfora do espaço público, o local, por excelência, de onde emergem as lutas sociais e o Direito" (SOUSA JÚNIOR, 2015, p.82) e os objetivos do curso Introdução Crítica ao Direito.

Não nos esqueçamos de que, assim como o Direito Achado na Rua, há duas escolas de teoria crítica do direito bastante combativas, o Direito Alternativo e o Direito Insurgente, que contribuíram para o pen- 
sar crítico e atuante dos ativistas e também das instituições jurídicas, a importância da disciplina Sociologia Jurídica como metodologia de combate nos cursos jurídicos brasileiros, unindo dialeticamente a teoria com a prática em sua ação transformadora por meio de projetos de extensão - como as assessorias cidadãs - junto a atores sociais/ sujeitos políticos de transformação.

As ideias concebidas por Lyra Filho e, posteriormente, por José Geraldo de Sousa Júnior, Roberto Aguiar e Alexandre Bernardino Costa deram solidez a um "caminhar prático-intelectual" do Direito Achado na Rua com a exemplificação de atuação em vários casos e conjunturas de lutas sociais, debates acadêmicos nacionais e internacionais, assim como críticas formuladas basicamente em torno da juridicidade, do sujeito coletivo e, principalmente, sobre se a Constituição de 1988, em seu advento de ascenso de cidadania, esgotou o projeto do Direito Achado na Rua, o que tornava um desafio e um convite à continuidade do projeto em luta, principalmente nesta nossa conjuntura atual, em que urge uma onda conservadora de efeitos inimagináveis que exige cuidadosa reflexão.

Há vários exemplos sobre a importância da interdisciplinaridade e as experiências concretas de atuação do Direito Achado na Rua, como os enumerados por Sousa Júnior (2015):

"Direito à Memória e à Moradia; Ceilândia: Mapa da Cidadania em Rede na Defesa dos Direitos Humanos e na formação do novo profissional do direito; Direitos Humanos e Gênero: Promotoras Legais Populares; Projeto UnB/Tribuna do Brasil: coluna de o Direito Achado na Rua; Projeto de Extensão Tororó; Observatório Permanente da Justiça brasileira; Educação Popular e Direitos Humanos: capacitação de atores sociais no Distrito Federal e Estado de Goiás" (SOUSA JÚNIOR, 2015, p.177).

Da mesma forma, há experiências inovadoras protagonizadas pelo Direito Achado na Rua: o Núcleo de Prática Jurídica da Faculdade de Direito da Universidade de Brasília; a Assessoria Jurídica Universitária Popular Roberto Lyra Filho - UnB; as Promotoras Legais Populares - UnB; o Centro de Referência em Direitos 
Humanos da Universidade Federal da Paraíba - UFPB: Grupo de Pesquisa e Extensão Loucura e Cidadania; os Novos Cursos de Formação em Direito - as já citadas Turmas do Programa Nacional de Educação na Reforma Agrária (PRONERA) e os Novos Cursos de Pós-Graduação em Direitos Humanos.

O Direito Achado na Rua também se insere, atualmente, no ângulo dos principais desafios - como as Jornadas de Junho de 2013 e o golpe jurídico-parlamentar-midiático de 2016 - tentando alcançar um balanço construtivo interligando as quase três décadas de criação e desenvolvimento dessa escola de teoria e práxis transformadora criada por Lyra Filho no seio da Universidade de Brasília (UnB); tentando intervir e responder aos dilemas hoje postos pela conjuntura de exceção do Estado brasileiro.

Reflexões analíticas como o pluralismo jurídico no contexto latino-americano com ênfase nos polêmicos processos constituintes de países como Venezuela, Bolívia e Equador, debate sobre o novo constitucionalismo brasileiro, a concepção crítica sobre as avaliações pedagógicas dos cursos de Direito pelo nosso país, o conceito de democracia ligado à participação popular, a criminalização dos movimentos sociais, a democratização da mídia, o ascenso do protagonismo conservador protofascista, dentre vários outros temas, necessitam de incisiva e oxigenada intervenção do movimento Direito Achado na Rua.

Para compreendermos o protagonismo atual do Direito Achado na Rua, analisaremos especificamente as ideias de Roberto Lyra Filho em sua, considerada por muitos, principal obra - ou a mais difundida "O Que é Direito?" (1982) da Coleção Primeiros Passos.

No primeiro tópico dessa obra, denominado "Direito e Lei", o autor demonstra comparações entre os significados semânticos e epistemológicos entre as palavras Direito e Lei, a relação dialética entre estas em determinadas conjunturas ideopolíticas e a conclusão de que "...não significa, porém, que é impossível determinar a 'essência' do Direito - o que, apesar de tudo, ele é, enquanto vai sendo: o que surge de constante, na diversidade, e que se denomina, tecnicamente, ontologia." (1982, p.6). 
No segundo tópico, intitulado "Ideologias Jurídicas", o autor divide sua definição em três classificações: a) ideologia como crença; b) ideologia como falsa consciência; c) ideologia como instituição (1982, p.8), ancorado em grandes pensadores de variados matizes ideológicos, como Marx e Engels, Ortega y Gasset, Adam Schaff e Kant.

No terceiro tópico - "Principais Modelos de Ideologia Jurídica"- Lyra Filho inicia sua argumentação demonstrando as duas mais influentes ideologias jurídicas: o direito natural e o direito positivo. Enquanto "o positivismo, de qualquer sorte, é uma redução do Direito à ordem estabelecida; o jusnaturalismo é, ao contrário, um desdobramento em dois planos: o que se apresenta nas normas e o que nelas deve apresentar-se para que sejam consideradas boas, válidas e legítimas" (1982, p.17).

Adentrando no tema supramencionado, Lyra Filho subdivide o positivismo em três tipos: o positivismo legalista; o positivismo historicista ou sociologista; e o positivismo psicologista; e o direito natural também em três formas: o direito natural cosmológico; o direito natural teológico; e o direito natural antropológico, mas que poderia escoar para um quarto tipo proposto por Michel Miaille: o direito natural de combate ou direito natural histórico-social. (LYRA FILHO, 1982)

No quarto tópico "Sociologia e Direito", o autor demonstra a importância das interpretações tanto da Sociologia quanto da Filosofia em torno do Direito e da Justiça e analisa dois modelos que se completam - apesar de diferenças formais de análise - em seus esquemas societários abarcando a infraestrutura e a superestrutura da sociedade capitalista e o lugar do Direito em ambos. O primeiro modelo é definido como "sociologia da estabilidade, harmonia e consenso" (1982, p.37) e o segundo como "sociologia da mudança, conflito e coação" (1982, p.39).

No último tópico do livro "O Que é Direito?", denominado "A Dialética Social do Direito", Roberto Lyra Filho apresenta o terceiro modelo inovador no sentido de superar a dicotomia entre direito positivo e direito natural: o modelo dialético. Este modelo apresenta pontos de referência, em que balizam aspectos contraditórios e dialéticos entre classes antagônicas que buscam a transformação da sociedade e, consequentemente, o Direito. 
Diante desse contexto há a clássica definição de Direito para Roberto Lyra Filho:

"Direito é processo, dentro do processo histórico: não é uma coisa feita, perfeita e acabada; é aquele vir-a-ser que se enriquece nos movimentos de libertação das classes e grupos ascendentes e que definha nas explorações e opressões que o contradizem, mas de cujas próprias contradições brotarão as novas conquistas". (LYRA FILHO, 1982, p.56).

Também ao final da obra há uma clara diferenciação entre Direito e Moral em que "a moral visa o aperfeiçoamento de cada um, dentro da honestidade. O Direito visa ao desdobramento da liberdade, dentro dos limites da coexistência". (LYRA FILHO, 1982, p.58).

Dessa forma, com a sucinta sistematização da apresentação do clássico "O Que é o Direito?" vimos que se trata de um pensamento fundamental para almejarmos um outro Direito, para além do majoritariamente ensinado e apreendido nas instituições, um Direito que, como diria Lênin, tem a pretensão de unir a teoria à prática revolucionária, e complementando-o, com o humanismo dialético a la Lyra Filho.

\section{CONSIDERAÇÕES FINAIS}

Apresentamos nesta singela contribuição um novo pensar político-pedagógico tendo como base três referências de teoria educacional crítica: a pedagogia marxista ou marxista-leninista, pós-Revolução Russa de 1917; a pedagogia do Movimento dos Trabalhadores Rurais Sem Terra MST; e a pedagogia difundida pelo Direito Achado na Rua, que tem em Roberto Lyra Filho seu principal expoente.

Tais pedagogias devem servir de parâmetros para uma crítica do ensino jurídico brasileiro do século XXI, pois estamos formando uma geração de juristas comprometidos com a manutenção do status quo, legalistas puros e pueris desprovidos de senso de justiça e igualdade, servindo como meros serviçais de conglomerados do poder normativo do capital financeiro (inter)nacional. 
Com base nas experiências apresentadas, devemos radicalizar na ação das seguintes concepções político-pedagógicas: projetos de extensão que forneçam ao estudante de Direito convívio com realidades sociais distantes de sua vivência, como assistência jurídica à população hipossuficiente, além de criação de uma cultura de troca de relatos vividos por gente do povo e suas mazelas cotidianas; alterações curriculares para envolver disciplinas com temáticas sociais e de discussão de pensadores brasileiros como Sérgio Buarque de Holanda, Raimundo Faoro, Caio Prado Júnior, Florestan Fernandes, Darcy Ribeiro entre tantos outros que tentaram compreender nossa realidade; possibilitar acesso a cursos sobre movimentos sociais de vários matizes, ministrados pelos próprios ativistas dos movimentos, como os sem-terra, sem-teto, mulheres, negros, índios, LGBTI's, para que os juristas possam atuar com sensibilidade jurídico-social, em prol de um legítimo Estado Democrático e Social de Direito.

Conhecer a experiência de nosso país, de nosso povo, ter uma formação humanista, possibilitar controle e transparência pela população de seus atos e funções, seriam elementos centrais para a formação de novos juristas para uma nova sociedade. Em um momento em que há um ascenso da nova-velha direita, com seu propósito de retirada agressiva de direitos sociais, individuais e coletivos, importante trazer para o debate as três referências pedagógicas aqui mencionadas, para que o Aparelho Ideológico e Repressivo do Estado (ALTHUSSER, 1983), que é o Direito burguês, venha a se tornar, pressionando pela contradição do sistema, uma disputa entre hegemonia e contra-hegemonia (GRAMSCI, 1968), para que possamos insuflar uma nova correlação de forças na tentativa de se criar um Direito humano e soberano que respeite os anseios dos mais necessitados e um projeto de país calcado na democracia.

É fundamental que possamos disputar esse espaço, para que cesse a quebra de valores normativos, perpetrada por representantes das castas mais privilegiadas do Sistema de Justiça no Brasil: procuradores, promotores e juízes de Direito que, em sua maioria, vem perseguindo e criminalizando ininterruptamente qualquer traço ou aspecto de progressismo no sistema político e social em que vivemos, açula- 
dos por um complexo midiático-empresarial concentrado e concentrador de poder e adesista convicto do projeto de rentistas beneficiários do capitalismo sem risco.

Dessa forma, este trabalho foi uma singela tentativa de sugestões pedagógicas para os formuladores do ensino jurídico brasileiro, para que possamos elucidar esse "Direito que se Ensina Errado" (LYRA FILHO, 1980) e tentarmos formar e ser formados tendo como referencial os valores mais caros da cidadania: o Estado Social e Democrático de Direito, a Liberdade e o respeito aos Direitos e Garantias Fundamentais.

Como relatou o jurista uruguaio Eduardo Couture, em seus Mandamentos do Advogado (1987): "LUTA. O seu dever é lutar pelo Direito; porém, quando encontrar o Direito em conflito com a Justiça, lute pela Justiça." Que as experiências político-pedagógicas aqui apresentadas sejam exemplo de atuação teórico-prática em nossa luta cotidiana pela Justiça.

\section{REFERÊNCIAS}

AGAMBEN, Giorgio. Estado de Exceção. São Paulo: Boitempo, 2004. ALTHUSSER, Louis. Aparelhos Ideológicos do Estado. São Paulo: Graal, 1983.

ANDERSON, Perry. Considerações sobre o Marxismo Ocidental: nas trilhas do materialismo histórico. São Paulo: Boitempo, 2004.

ARCARY, Valério. As Esquinas Perigosas da História: Situações revolucionárias em perspectiva marxista. São Paulo: Xamã, 2004.

BARAN, Paul. A Economia Política do Desenvolvimento. São Paulo: Nova Cultural, 1986.

BENJAMIN, César. Brasil: Crise e Destino: Expressão Popular: São Paulo, 2000.

BOBBIO, Norberto. MATTEUCCI, Nicola. PASQUINO, Gianfranco. Dicionário de Política: UNB: Brasília, 2004. 
BRASIL. Constituição da República Federativa do Brasil - 1988. Brasília: Senado Federal, 2018.

BRASIL. Decreto $n^{\circ} 7.352$, de 4 de novembro de 2010. Disponível em http://portal.mec.gov.br/docman/marco-2012-pdf/10199-8-decreto7352-de4-de-novembro-de-2010/file. Acesso em 19 de agosto de 2019.

CAIXETA, Marcelo et al. Vigotski: Psiquiatria/Psicologia do Desenvolvimento. Goiânia: UFG, 2015.

CALDART, Roseli Salete. Pedagogia do Movimento Sem Terra: São Paulo: Expressão Popular, 2004.

CHAUÍ, Marilena. Simulacro e Poder: uma Análise da Mídia. São Paulo: Perseu Abramo, 2006.

COUTURE, Eduardo. Os Mandamentos do Advogado. Porto Alegre: Sergio Antonio Fabris, 1987.

GRAHAM, Stephen. Cidades Sitiadas: o Novo Urbanismo Militar. São Paulo: Boitempo, 2016.

GRAMSCI, Antônio. Os Intelectuais e a Organização da Cultura. Rio de Janeiro: Civilização Brasileira, 1968.

HARVEY, David. Os Enigmas do Capital e as Crises do Capitalismo. São Paulo: Boitempo, 2011.

KLEIN, Naomi. A Doutrina do Choque: A Ascensão do Capitalismo de Desastre. São Paulo: Nova Fronteira, 2008.

LAMOUNIER, Bolívar. "Advocacia se proletarizou e não é mais o celeiro das elites políticas". In Consultor Jurídico. São Paulo, 4 de agosto de 2018. Disponível em https://www.conjur.com.br/2018-ago-04/ entrevista-bolivar-lamounier-sociologo-cientista-politico Acesso em 19 de agosto de 2019.

LÊNIN, Vladimir. As três fontes: São Paulo: Expressão Popular, 2001. 
LUEDEMANN, Cecília da Silveira. Anton Makarenko, Vida e Obra a pedagogia na revolução: São Paulo: Expressão Popular, 2005.

LUKÁCS, György. Para uma Ontologia do Ser Social: São Paulo: Boitempo, 2012.

LUNATCHARSKI, Anatoli. A Educação na Rússia Revolucionária: São Paulo: Causa Operária, 2002.

LYRA FILHO, Roberto. Karl, meu amigo: diálogo com Marx sobre o Direito. Porto Alegre: Safe; IAB-RS, 1983.

. O que é Direito? São Paulo: Brasiliense, 1982.

O Direito que se Ensina Errado. Brasília: CADIR UnB, 1980.

KORSCH, Karl. Marxismo e Filosofia. Rio de Janeiro: UFRJ, 2008.

KRUPSKAIA, Nadezhda. A Construção da Pedagogia Socialista. São Paulo: Expressão Popular, 2017.

MAKARENKO, Anton. Poema Pedagógico: São Paulo: Ed. 34, 2012.

MARX, karl. As lutas de classes na França de 1848 a 1850 . São Paulo: Boitempo, 2012.

.Crítica ao Programa de Gotha. São Paulo: Boitempo, 2012.

. O Capital. Vol 3: São Paulo: Boitempo, 2016.

. Contribuição à Crítica da Economia Política. São Paulo: Martins Fontes, 2003.

PINK FLOYD. The Wall. Direção artística: Roger Waters. Nova York: Columbia, 1979.

PISTRAK, Moisey. Fundamentos da Escola do Trabalho: São Paulo: Expressão Popular, 2008.

RANCIĖRE, Jacques. O Ódio à Democracia. São Paulo: Boitempo, 2014. 
ROSENBERG, Arthur. História do Bolchevismo. Belo Horizonte: Oficina de Livros, 1989.

ROTHER, Edna Terezinha. Revisão Sistemática x Revisão Narrativa. In Acta Paulista de Enfermagem, São Paulo, Vol.20. n.2. Editorial. Abr/Jun 2007. Disponível em http://www.redalyc.org/ pdf/3070/307026613004.pdf Acesso em 19 de agosto de 2019.

SERRANO, Pedro. Autoritarismo e Golpes na América Latina: Breve Ensaio sobre Jurisdição e Exceção. São Paulo: Alameda, 2016.

SOUSA JÚNIOR, José Geraldo. O Direito Achado na Rua: Concepção e Prática - Coleção Direito Vivo - Vol. 2. Rio de Janeiro: Lumen Juris, 2015.

TRAGTENBERG, Maurício. Marxismo Heterodoxo. São Paulo: Brasiliense, 1981.

VYGOTSKY, Lev Semenovich. Pensamento e Linguagem. São Paulo: Martins Fontes, 2008.

WOLKMER, Antônio Carlos. Introdução ao Pensamento Jurídico Crítico. São Paulo: Saraiva, 2009. 